\title{
BENEFÍCIOS DO EXERCÍCIO FÍSICO INTRADIALÍTICO: REVISÃO SISTEMÁTICA
}

\section{BENEFICIOS DEL EJeRCICIO FISICO INTRADIALÍTICO: REVISIÓN SISTEMÁtICA}

\author{
Benefits of Intradialitic Physical Exercise: Systematic Review
}

\author{
DOI 10.33194/rper.2020.v3.n2.7.5800 | Submetido 12/08/2020 | Aprovado 15/12/2020
}

\author{
André Martins $^{1} \mathbb{D}$; Carla Ribeiro² ${ }^{\mathbb{D}}$; Carlos Ribeiro ${ }^{3} \mathbb{D}$; Fatima Lopes $^{2} \mathbb{D}$; João Oliveira² ${ }^{\mathbb{C}}$ \\ 1 - Diaverum - Unidade de Riba de Ave (Centro de Hemodiálise); 2 - Centro Hospitalar Universitário de São João; \\ 3 - Instituto Português de Oncologia do Porto Francisco Gentil
}

\section{RESUMO}

Introdução: De acordo com os dados da Sociedade Portuguesa de Nefrologia, em Portugal a 31 de dezembro de 2018 efetuavam tratamento de Hemodiálise (HD) 12.227 doentes. Os doentes portadores de doença renal crónica (DRC) submetidos a tratamento dialítico, apresentam alterações físicas e psicológicas que predispõem ao sedentarismo. Tem risco superior de mortalidade devido á capacidade funcional reduzida e perda de força muscular, quando comparados com indivíduos da mesma idade. A evidência científica aponta para a implementação de programas regulares de exercício como tratamento coadjuvante para estes indivíduos.

Objetivo: Reunir e caraterizar, a evidência científica existente sobre os benefícios do exercício físico intradialítico (EFI), que sustente a futura implementação de um programa de EFI num centro de hemodialise.

Método: A pesquisa foi efetuada nas bases de dados eletrónicas internacionais da EBSCOhost Web, em abril e maio 2020, tendo sido obtido inicialmente um total de 2,602 produções científicas. Foram selecionados para analise final 19 estudos, 2 estudos quasi-experimentais e 17 estudos randomizados controlados (RCT), que cumpriam os critérios de inclusão.

Resultados: A análise da evidência científica obtida, orienta para 3 categorias de intervenção: EFI aeróbio, EFI resistido e EFI combinado (aeróbio e resistido). Todos os programas de exercício físico apresentam benefícios em um ou mais parâmetros: eficácia da hemodialise (Kt/V); capacidade física funcional; depressão; qualidade de vida (QV); força muscular; alterações cardiovasculares; atividade física diária; sono; equilíbrio e síndrome de pernas inquietas.

Conclusão: A literatura encontrada permite-nos concluir que programas de EFI são de execução simples e pouco dispendiosos, apresentam vários benefícios para os hemodialisados sem prejuízo da eficácia dialítica.

Palavras-Chave: hemodialise, exercício intradialíatico, benefícios, qualidade de vida, ganhos em saúde

\section{RESUMEN}

Introducción: Según datos de la Sociedad Portuguesa de Nefrología, en Portugal el 31 de diciembre de 2018, 12.227 pacientes se sometieron a tratamiento de Hemodiálisis (HD). Los pacientes con enfermedad renal crónica (ERC) sometidos a diálisis, presentan cambios físicos y psicológicos que los predisponen a un estilo de vida sedentario. Tiene un mayor riesgo de mortalidad debido a la reducción de la capacidad funcional y la pérdida de fuerza muscular en comparación con individuos de la misma edad. La evidencia científica apunta a la implementación de programas de ejercicio regular como tratamiento complementario para estas personas.

Objetivo: Recopilar y caracterizar la evidencia científica existente sobre los beneficios del ejercicio físico intradialítico (EFI), que apoye la futura implementación de un programa de EFI en un centro de hemodiálisis.

Método: La investigación se llevó a cabo en las bases de datos electrónicas internacionales de EBSCOhost Web, en abril y mayo de 2020 , habiéndose obtenido inicialmente un total de 2.602 producciones científicas. Se seleccionaron para el análisis final 19 estudios, 2 estudios cuasiexperimentales y 17 estudios controlados aleatorios (ECA), que cumplieron con los criterios de inclusión.

Resultados: El análisis de la evidencia científica obtenida, orienta a 3 categorías de intervención: EFI aeróbico, EFI resistido y EFI combinado (aeróbico y resistido). Todos los programas de ejercicio físico tienen beneficios en uno o más parámetros: efectividad de la hemodiálisis (Kt / V); capacidad física funcional; depresión; calidad de vida (QOL); fuerza muscular; cambios cardiovasculares; actividad física diaria; dormir; síndrome de equilibrio y piernas inquietas.

Conclusión: La literatura encontrada permite concluir que los programas EFI son simples y económicos de implementar, tienen varios beneficios para los pacientes en hemodiálisis sin perjuicio de la eficacia de la diálisis.

Palabras clave: hemodiálisis, ejercicio intradialítico, beneficios, calidad de vida, beneficios para la salud. 
Introduction: According to data from the Portuguese Society of Nephrology, in Portugal on December 31 of 2018, 12,227 patients underwent hemodialysis treatment (HD). Patients with chronic kidney disease (CKD) on dialysis present physical and psychological limitations that induce to a sedentary life stile. They have a higher risk of mortality due to reduced functional capacity and loss of muscle strength when compared to individuals of the same age. Scientific evidence points to the implementation of regular exercise programs as supporting treatment for these individuals.

Objectives: Gather and characterize the existing scientific evidence of the benefits of intradialitic physical exercise (IFE), which supports the future implementation of an IFE program in a hemodialysis center.

Method: The research was carried out in the EBSCOhost databases, in April and May 2020, having initially obtained a total of 2,602 scientific productions. Were selected for final analysis 19 studies, 2 quasi-experimental studies and 17 randomized controlled studies, which met the inclusion criteria.

Results: The analysis of the scientific evidence guides to 3 intradialitic intervention categories: aerobic physical exercise, resistance physical exercise and combined physical exercise (aerobic and resistance). All exercise programs have benefits in one or more parameters: hemodialysis effectiveness; functional physical capacity; depression; quality of life; muscle strength; cardiovascular changes; daily physical activity; sleep; balance and restless legs syndrome.

Conclusion: The literature founded, allows us to conclude that IFE programs are simple and inexpensive to implement, have several benefits for hemodialysis patients without prejudice to the dialysis efficacy.

Keywords: hemodialysis, intradialitic exercise, benefits, quality of life, health gains

\section{INTRODUÇÃO}

A Doença Renal Crónica (DRC) foi declarada em todo o mundo como uma questão de saúde pública. 0 aumento do diagnóstico de DRC é multifatorial e, em parte, está associado ao envelhecimento da população. A maioria dos doentes com DRC apresenta uma ou mais condições, comorbilidades, com predomínio em algumas etnias e grupos socioeconómicos mais desfavorecidos. Se combinarmos estas condições com o aumento da tendência para a obesidade e a prevalência de diabetes, podemos prever uma epidemia de DRC ${ }^{(1)}$.

Segundo Feehally (2), nos países desenvolvidos, o número de casos de diabetes mellitus ou hipertensão arterial identificados como a principal causa de DRC em fase terminal com necessidade de terapêutica renal substitutiva (TRS) tem vindo a aumentar rapidamente desde 1980, substituindo a glomerulonefrite como causa principal desde os anos 90 .

De acordo com o National Kidney Foundation (3), a DRC é definida como danos nos rins ou taxa de filtração glomerular (TFG) $<60 \mathrm{ml} / \mathrm{min} / 1,73 \mathrm{~m} 2$ durante 3 meses ou mais. Os danos nos rins são definidos como anomalias patológicas ou marcadores de dano, incluindo alterações nos exames de sangue ou urina ou estudos de imagem. Os estádios da DRC são baseados principalmente na TFG medida ou estimada.

Ao alcançar o último estadio da DRC, uma das opções, é o tratamento de substituição renal por hemodialise, normalmente realizada três vezes por semana durante 3-5 horas, num hospital ou clínica. De acordo com os dados da Sociedade Portuguesa de Nefrologia, em Portugal (4) a 31 de dezembro de 2018 efetuavam tratamento de hemodiálise (HD) 12.227 doentes.

O sistema de HD inclui um circuito de sangue extracorporal e um circuito de líquido de diálise. 0 sangue é bombeado no circuito extracorporal a partir do acesso vascular para o dialisador e, em seguida, é devolvido aos doentes. Segundo Astor et al (5), um acesso vascular funcional é crucial e tem sido claramente demonstrado que a prática clínica tem um impacto importante no desempenho do acesso.

Kosmadakis et al. (6), refere que a própria insuficiência renal crónica (IRC) e a HD, pelo síndrome urémico, pelo catabolismo e pela neuromiopatia urémica, a que submetem a pessoa, provocam limitações da capacidade funcional e perda da força muscular. Os doentes têm de fazer mudanças enormes nas suas vidas que envolvem um compromisso vitalício com um tratamento que não fornece uma cura.

Os estilos de vida têm uma enorme influência na saúde e na qualidade de vida. A falta de atividade física, ou sedentarismo, contribui para o aparecimento ou agravamento de várias patologias, ${ }^{(7)}$.

Segundo a Organização Mundial de Saúde (8), a participação em programas regulares de atividade física reduz o risco de doenças cardiovasculares, diabetes mellitus (DM), hipertensão arterial, cancro do colon e da mama e depressão. Adicionalmente a atividade física é determinante no gasto de energia e fundamental no controlo de peso.

Os efeitos do exercício físico em IRC em programa de $\mathrm{HD}$, são discutidos há vários anos. Os principais objetivos de programas de reabilitação são permitir aos doentes melhorar ou manter os seus níveis funcionais físicos, sensoriais, intelectuais, psicológicos e sociais.

Moura et al (9), referem que a maioria demonstrou que exercícios físicos realizados durante a HD promovem efeitos benéficos na melhoria da capacidade aeróbia, força muscular e no controle dos fatores de risco cardiovasculares, auxiliando a remoção dos solutos durante a HD.

Segundo Parsons, Toffelmire e King-VanVlack ${ }^{(10)}$, o exercício intradialítico é uma intervenção que favorece a adesão, a motivação e facilita a monitorização. Também, Reboredo et al. ${ }^{(11)}$ refere que os programas 
de exercício durante a HD trazem vantagens adicionais, tais como, maior adesão, a conveniência do horário, reduzem a monotonia do tratamento e facilitam o acompanhamento médico.

O objetivo desta revisão sistemática é reunir e caraterizar, a evidência científica existente sobre os benefícios do EFI, que sustente a futura implementação de um programa de EFI num centro de hemodialise.

\section{METODOLOGIA}

Para responder ao objetivo definido, optou-se pela realização de uma pesquisa integrativa da literatura e definiu-se a seguinte questão de investigação:

\section{Nos indivíduos com IRC, qual o benefício do exercício físico intradialítico?}

Para a seleção dos artigos procedemos á definição de critérios de inclusão e exclusão e a identificação dos termos descritores relacionados com cada um dos componentes da estratégia PI[C]OD (Participantes, Intervenções, Comparações, Outcomes e Desenho de estudo), (12) (Tabela1).

Tabela 1- Pergunta PICOD, critérios de inclusão e exclusão

\begin{tabular}{|c|c|c|}
\hline PICO & Critérios Inclusão & Critérios Exclusão \\
\hline 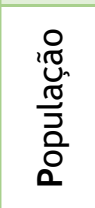 & $\begin{array}{l}\text { Indivíduos com IRC em tratamento } \\
\text { com hemodiálise (HD) com idade } \\
\text { superior ou igual a } 18 \text { anos }\end{array}$ & $\begin{array}{l}\text { Indivíduos com IRC que } \\
\text { não se encontram em } \\
\text { tratamento com HD } \\
\text { Indivíduos com idade } \\
\text { inferior a } 18 \text { anos }\end{array}$ \\
\hline 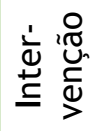 & $\begin{array}{l}\text { Programas de exercício físico } \\
\text { regular realizado durante o } \\
\text { tratamento de HD }\end{array}$ & $\begin{array}{l}\text { Programas de exercício } \\
\text { físico realizado fora da } \\
\text { sessão de HD }\end{array}$ \\
\hline \multirow{3}{*}{ 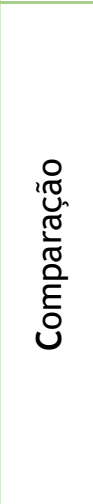 } & $\begin{array}{l}\text { Estudos que comparem programas } \\
\text { de exercício físico nos indivíduos } \\
\text { com IRC realizado durante a HD } \\
\text { com a não realização de exercício } \\
\text { físico } \\
\text { Estudos que comparem diferentes }\end{array}$ & \multirow{3}{*}{$\begin{array}{l}\text { Estudos cujos } \\
\text { participantes realizem } \\
\text { exercício físico } \\
\text { durante e fora da } \\
\text { sessão de HD } \\
\text { Estudos cujos } \\
\text { participantes realizem } \\
\text { exercício físico fora da } \\
\text { sessão de HD }\end{array}$} \\
\hline & $\begin{array}{l}\text { tipos de exercício físico nos } \\
\text { indivíduos com IRC em HD }\end{array}$ & \\
\hline & $\begin{array}{l}\text { Estudos que apresentem resultados } \\
\text { com a implementação de } \\
\text { programas de exercício durante a } \\
\text { HD em indivíduos que não } \\
\text { realizavam exercício }\end{array}$ & \\
\hline 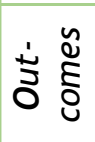 & $\begin{array}{l}\text { Ganhos em saúde } \\
\text { Benefícios } \\
\text { Qualidade de vida }\end{array}$ & \\
\hline 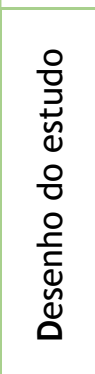 & $\begin{array}{l}\text { Estudos experimentais, quási- } \\
\text { experimentais e revisões } \\
\text { sistemáticas da literatura de } \\
\text { estudos experimentais, quási- } \\
\text { experimentais centrados na } \\
\text { temática da avaliação da } \\
\text { efetividade de programas de } \\
\text { exercício físico, dirigidos aos } \\
\text { indivíduos com IRC realizados } \\
\text { durante a HD }\end{array}$ & $\begin{array}{l}\text { Estudos descritivos } \\
\text { Estudos sem grupo de } \\
\text { controlo. }\end{array}$ \\
\hline
\end{tabular}

Para além dos critérios de inclusão e exclusão expostos, definimos critérios que poderão condicionar viés de publicação e linguagem (13). De forma a obter a produção científica mais atualizada, foram incluídas apenas as produções científicas publicadas entre 20102020, em texto integral e redigidas em inglês, espanhol e português.

Para clarificar e formular os termos de pesquisa, de forma mais pormenorizada e abrangente, recorremos aos descritores em ciências da saúde, acedemos ao DeCS Browser e, quando apropriado, progredíamos para - MeSH Browser. Na pesquisa foram utilizados os seguintes descritores: Hemodialysis; Dialysis; Exercise Training; Physical Exercise; Physical Activity; Exercise; Intradialysis Exercise; Outcomes; Benefits; Quality of life; Health gains.

Toda a metodologia de busca foi realizada de acordo com as diretrizes do protocolo de apresentação de revisões sistemáticas PRISMA (14). A pesquisa da evidência foi efetuada nos meses de abril e maio de 2020, nas bases de dados da EBSCOhost Web, como a Academic Search Complete, Business Source Complete, CINAHL Complete, CINAHL Plus with Full Text, ERIC, Library, Information Science \& Technology Abstracts, MedicLatina, MEDLINE with Full Text, Psychology and Behavioral Sciences Collection, Regional Business News, SPORTDiscus with Full Text.

$\mathrm{Na}$ estratégia de pesquisa utilizou-se uma estrutura lógica que combinou os termos de busca, os operadores Booleanos e os componentes da estratégia PICOD. 0 processo de seleção da literatura foi realizado por cinco revisores, que analisaram de forma independente os títulos e resumos dos artigos segundo os mesmos critérios.

Foi extraída informação resumida de cada artigo, para análise crítica e apresentação da evidência encontrada.

A opção metodológica para identificar os níveis de evidência dos estudos incidiu sobre Joanna Briggs Institute (15), através do instrumento "Levels of Evidence for Effectiveness", que define 5 níveis de evidência. Este instrumento parece reunir acordo na comunidade científica, sendo largamente utilizado em outros estudos ${ }^{(16)}$.

Para avaliação da qualidade metodológica dos estudos utilizou-se a check list for case control studies ${ }^{(14)}$. A avaliação da qualidade realizou-se de forma independente por cinco elementos, divididos em grupos de dois, de forma a garantir uma análise rigorosa. $\mathrm{Na}$ falta de consenso entre os avaliadores, estes reuniram de forma a obter unanimidade na avaliação do estudo em questão, evitando viés.

\section{RESULTADOS}

A primeira seleção foi realizada pelos limites de pesquisa presentes na base de dados, o que excluiu alguns artigos. Foram-se incluindo mais descritores de forma a refinar a pesquisa para obter os artigos mais relevantes (tabela 2 ). 
Tabela 2- Query de pesquisa

\begin{tabular}{|l|c|}
\hline \multicolumn{1}{|c|}{ Frase Booleana } & Artigos \\
\hline (Hemodialysis OR dialysis) AND exercise & 2,602 \\
\hline (AB (Hemodialysis OR dialysis)) AND AB exercise & 476 \\
\hline TI (Hemodialysis OR dialysis) AND TI (Exercise & \\
\hline $\begin{array}{l}\text { Training OR Physical Exercise OR Physical } \\
\text { Activity OR exercise OR intradialysis exercise) }\end{array}$ & 231 \\
\hline \begin{tabular}{l|} 
(TI (TI (Hemodialysis OR dialysis) AND TI \\
(Exercise Training OR Physical Exercise OR
\end{tabular} & \\
$\begin{array}{l}\text { Physical Activity OR exercise OR intradialysis } \\
\text { exercise))) AND AB (Outcomes OR benefits OR } \\
\text { quality of life OR health gains) }\end{array}$ & 127 \\
\hline
\end{tabular}

$A B$ - Abstract; TI-Titulo

Após a seleção de 127 artigos para analise, foram excluídos 30 por se encontrarem repetidos. Os artigos restantes foram lidos e de acordo com os critérios de inclusão e exclusão, selecionaram-se 19 artigos analise (Figura1).

Tendo como objetivo a análise final e extração dos dados, realizou-se uma tabela que condensa a evidência recolhida dos 19 artigos filtrados, com referência ao estudo (título, autor, ano de publicação e país), desenho, nível de evidência e qualidade metodológica, amostra, objetivo, intervenção, duração e frequência, escalas de avaliação e resultados obtidos (Tabela 3).

Após a sumarização dos resultados, optou-se por criar categorias entre os estudos que apresentavam semelhanças entre si. Esta categorização teve como base as áreas de intervenção estudadas e os seus efeitos. Assim, selecionamos as seguintes categorias: função motora (capacidade física funcional, a força muscular e o equilíbrio), depressão, qualidade de vida, atividade física, sono, eficácia da hemodialise e síndrome das pernas inquietas.

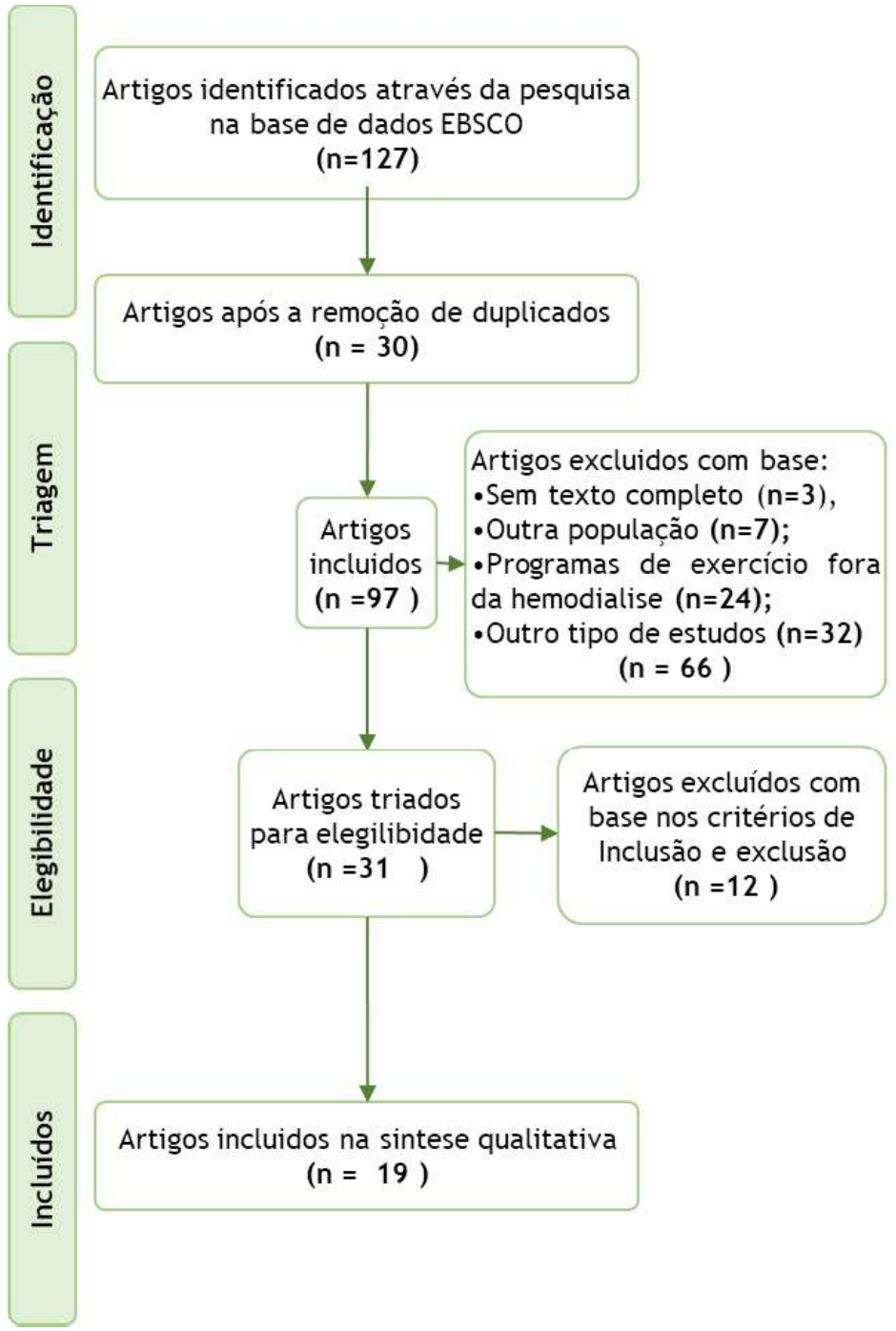

Figura 1- Protocolo de Pesquisa e Seleção de artigos (PRISMA)

Tabela 3- Resumo dos estudos incluídos para revisão

\begin{tabular}{|c|c|c|c|c|c|c|c|c|c|}
\hline E & $\begin{array}{c}\text { Título Estudo, Pais, } \\
\text { Ano }\end{array}$ & Autor & TE & NE & $\mathbf{N}$ & Objetivo & $\begin{array}{l}\text { Intervenção/ } \\
\text { Exercício }\end{array}$ & $\begin{array}{l}\text { Duração/ } \\
\text { Frequência }\end{array}$ & Avaliação \\
\hline 1 & $\begin{array}{l}\text { Effects of Exercise } \\
\text { Training Combined with } \\
\text { Virtual Reality in } \\
\text { Functionality and } \\
\text { Health-Related Quality } \\
\text { of Life of Patients on } \\
\text { Hemodialysis.Brasil } \\
2019\end{array}$ & $\begin{array}{l}\text { Maynard, } \\
\text { L. G., et } \\
\text { al. }\end{array}$ & RCT & 1.c & 45 & $\begin{array}{l}\text { Avaliar os efeitos do } \\
\text { treino físico combinado } \\
\text { com Realidade virtual } \\
\text { (RV) na funcionalidade } \\
\text { e qualidade de vida } \\
\text { (QV) de doentes em HD }\end{array}$ & $\begin{array}{l}\text { Grupo controlo: sem } \\
\text { intervenção } \\
\text { Grupo de intervenção: } \\
\text { Exercício aeróbio (EA) } \\
\text { e exercício resistido } \\
\text { (ER) } \\
\text { guiado por realidade } \\
\text { virtual }\end{array}$ & $\begin{array}{l}\text { 3/ Semana, } \\
\text { Nas } 2 \text { primeiras } \\
\text { horas de } \\
\text { hemodialise } \\
\text { 30' a } 60 \text { '. } \\
\text { Durante } 12 \\
\text { semanas. }\end{array}$ & $\begin{array}{l}\text { Borg scale } \\
\text { Avaliação de: Tensão Arterial (TA), } \\
\text { Frequência cardíaca (FC), Frequência } \\
\text { Respiratória (FR) e Saturação de } \\
\text { Oxigénio (StO2) } \\
\text { S Resultados clínicos } \\
\text { Walking speed } \\
\text { Timed up and go (TUG)) } \\
\text { Duke Activity Status (DASI) } \\
\text { Index } \\
\text { Health-related quality of life (HQoL) } \\
\text { Depressive symptoms (Scale } \\
\text { Depression) }\end{array}$ \\
\hline 2 & $\begin{array}{l}\text { Intradialytic exercise } \\
\text { improves physical } \\
\text { function and reduces } \\
\text { intradialytic hypotension } \\
\text { and depression in } \\
\text { hemodialysis patients. } \\
\text { Corea Sul } \\
2017\end{array}$ & $\begin{array}{l}\text { Rhee, S. } \\
\text { Y., et. al }\end{array}$ & QE & 2.d & 22 & $\begin{array}{l}\text { Avaliar os aspetos } \\
\text { físicos, psicológicos, } \\
\text { laboratoriais, e efeitos } \\
\text { relacionados à diálise } \\
\text { do exercício } \\
\text { Intradialítico }\end{array}$ & $\begin{array}{l}\text { Grupo: EA } \\
\text { Grupo: ER }\end{array}$ & $\begin{array}{l}\text { Todas as } \\
\text { sessões de } \\
\text { diálise, entre } \\
\text { 30' a 45'. } \\
\text { Durante } 6 \\
\text { meses. }\end{array}$ & $\begin{array}{l}\text { Teste de sentar e repousar; } \\
\text { Teste de caminhada de 6' } \\
\text { Beck Depression Inventory } \\
\text { Short Form-36 }\end{array}$ \\
\hline
\end{tabular}




\begin{tabular}{|c|c|c|c|c|c|c|c|c|c|}
\hline E & $\begin{array}{c}\text { Título Estudo, Pais, } \\
\text { Ano }\end{array}$ & Autor & TE & NE & $N$ & Objetivo & $\begin{array}{l}\text { Intervenção/ } \\
\text { Exercício }\end{array}$ & $\begin{array}{l}\text { Duração/ } \\
\text { Frequência }\end{array}$ & Avaliação \\
\hline 3 & $\begin{array}{l}\text { A pilot study } \\
\text { investigating the effect } \\
\text { of pedalling exercise } \\
\text { during dialysis on 6-min } \\
\text { walking test and hand } \\
\text { grip and pinch } \\
\text { strength. Reino Unido } \\
2019\end{array}$ & $\begin{array}{l}\text { Desai, } \\
\text { M., et. al }\end{array}$ & RCT & 1.c & 13 & $\begin{array}{l}\text { Determinar se um } \\
\text { programa de exercícios } \\
\text { com pedaleira } \\
\text { intradialítica } \\
\text { beneficiaria os doentes } \\
\text { em termos de força } \\
\text { muscular, }\end{array}$ & $\begin{array}{l}\text { Grupo de controlo - } \\
\text { sem intervenção } \\
\text { Grupo de intervenção: } \\
\text { EA, ER }\end{array}$ & $\begin{array}{l}3 \text { a } 5 / \text { semana, } \\
20^{\prime} \text { a } 60^{\prime} . \\
\text { Durante } 4 \\
\text { meses. }\end{array}$ & $\begin{array}{l}\text { Teste de caminhada de } 6^{\prime} \text {. } \\
\text { Força de preensão manual e força de } \\
\text { pinça. }\end{array}$ \\
\hline 4 & $\begin{array}{l}\text { Effects of acute } \\
\text { intradialytic exercise on } \\
\text { cardiovascular responses } \\
\text { in hemodialysis } \\
\text { patients. USA } \\
2018\end{array}$ & $\begin{array}{l}\text { Jeong, J. } \\
\text { H., et. al }\end{array}$ & RCT & $1 . c$ & 12 & $\begin{array}{l}\text { Avaliar a segurança do } \\
\text { exercício físico } \\
\text { Intradialítico e efeitos } \\
\text { hemodinâmicos a nível } \\
\text { cardiovascular }\end{array}$ & 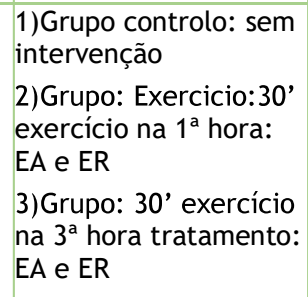 & $\begin{array}{l}\text { 3/ semana, } \\
30^{\prime} \text { em tempos } \\
\text { diferentes do } \\
\text { tratamento. } \\
\text { Durante } \\
\text { 12semanas }\end{array}$ & $\begin{array}{l}\text { Antes e após a HD: Balanço hídrico, FC } \\
\text { s e Ecocardiograma Durante a HD: TA } \\
\text { (15'); FC/h, Variação ritmo cardíaco } \\
\text { contínuo, Índice de aumento, Volume } \\
\text { Sangue, Resistidos Periférica total, } \\
\text { Vigilância de sinais hipotensão. }\end{array}$ \\
\hline 5 & $\begin{array}{l}\text { Effectiveness of } \\
\text { Intradialytic Exercise on } \\
\text { Dialysis Adequacy, } \\
\text { Physiological } \\
\text { Parameters, Biochemical } \\
\text { Markers and Quality of } \\
\text { Life-APilot Stud. India } \\
2018\end{array}$ & $\begin{array}{l}\text { Palucham } \\
\text { y, T., \& } \\
\text { Vaidyana } \\
\text { than, R. }\end{array}$ & RCT & $1 . c$ & 20 & $\begin{array}{l}\text { Determinar a eficácia } \\
\text { do exercício } \\
\text { Intradialítico na } \\
\text { eficácia da diálise, } \\
\text { parâmetros fisiológicos, } \\
\text { marcadores } \\
\text { bioquímicos e } \\
\text { qualidade de vida }\end{array}$ & $\begin{array}{l}\text { 1) Grupo Controlo - } \\
\text { sem intervenção } \\
\text { 2) Grupo de } \\
\text { intervenção: EA e ER }\end{array}$ & $\begin{array}{l}\text { 3/semana, } \\
10 \text { a } 15 ', \\
\text { durante as } \\
\text { primeiras } 2 \text { h } \\
\text { de sessão de } \\
\text { HD } \\
\text { Durante } 12 \\
\text { semanas }\end{array}$ & $\begin{array}{l}\text { Kt/V } \\
\text { TA } \\
\text { Peso } \\
\text { Kidney Disease Quality of Life Short } \\
\left.\text { Form (KDQOL-SF }{ }^{\mathrm{M}}\right)\end{array}$ \\
\hline 6 & $\begin{array}{l}\text { Effect of intradialytic } \\
\text { exercise on daily } \\
\text { physical activity } \\
\text { and sleep quality in } \\
\text { maintenance } \\
\text { hemodialysis patients. } \\
\text { Coreia do Sul } \\
2018\end{array}$ & $\begin{array}{l}\text { Cho, J.- } \\
\text { H., et. al }\end{array}$ & $\mathrm{RCT}$ & $1 . c$ & 46 & $\begin{array}{l}\text { Avaliar o efeito do } \\
\text { exercício Intradialítico } \\
\text { nas atividades de vida } \\
\text { diária e na qualidade } \\
\text { do sono, medida por } \\
\text { acelerómetro }\end{array}$ & $\begin{array}{l}\text { 1) Grupo Controlo- só } \\
\text { alongamentos } \\
\text { 2) Grupo: EA } \\
\text { 3) Grupo: ER } \\
\text { 4) Grupo: EA e ER }\end{array}$ & $\begin{array}{l}3 \text { / semana } \\
5 \text { 'até max. } 30 \text { ', } \\
\text { com } 5 \text { ' } \\
\text { arrefecimento } \\
\text { Durante } 12 \\
\text { semanas }\end{array}$ & $\begin{array}{l}\text { Wactisleep-bt accelerometer, usado no } \\
\text { braço, durante um período contínuo de } \\
7 \text { dias. } \\
\text { MET (kcal/h/Kg) } \\
\text { Sleep fragmentation índex - SF }\end{array}$ \\
\hline 7 & $\begin{array}{l}\text { Impact of Intradialytic } \\
\text { Exercise Intensity on } \\
\text { Urea Clearance in } \\
\text { Hemodialysis } \\
\text { Patients.Canadá } \\
2017\end{array}$ & $\begin{array}{l}\text { Brown, } \\
\text { P. D. } \\
\text { S.,et. Al }\end{array}$ & RCT & $1 . c$ & 22 & $\begin{array}{l}\text { Avaliar se o exercício } \\
\text { físico apresenta } \\
\text { benefícios ao nível da } \\
\text { eficácia do tratamento } \\
\text { de HD. }\end{array}$ & $\begin{array}{l}\text { 1) Grupo controlo: sem } \\
\text { controlo } \\
\text { 2) Grupo com EA com } \\
\text { intensidade até } 55 \% \text { do } \\
\text { ritmo cardíaco (HR) } \\
\text { max/ dia } \\
\text { 3)Grupo com EA até } \\
70 \% \text { HRmax /dia } \\
3 \text { Grupos em estudo. } \\
\text { Aeróbico e de } \\
\text { resistidos }\end{array}$ & $\begin{array}{l}3 / \text { semana } \\
30^{\prime}, \text { ou } 60^{\prime} \text { de } \\
\text { HD } \\
\text { Durante } 3 \\
\text { semanas. }\end{array}$ & $\begin{array}{l}\text { Kt/V } \\
\text { Borg Scale }\end{array}$ \\
\hline 8 & $\begin{array}{l}\text { Intradialytic exercise } \\
\text { and postural control in } \\
\text { patients with chronic } \\
\text { kidney disease } \\
\text { undergoing hemodialysis. } \\
\text { Brasil } \\
2017\end{array}$ & $\begin{array}{l}\text { Carletti, } \\
\text { C. O.,et. } \\
\text { al }\end{array}$ & RCT & $1 . c$ & 7 & $\begin{array}{l}\text { Avaliar o efeito do } \\
\text { exercício Intradialítico } \\
\text { sobre o equilíbrio } \\
\text { postural. }\end{array}$ & $\begin{array}{l}2 \text { grupos de acordo } \\
\text { com o dia da semana. } \\
\text { 1) sem carga, } 30-45 \text { 'de } \\
\text { treino intercalado } \\
\text { 2) sem carga, } 50-60 \text { ' } \\
\text { contínuo } \\
\text { 3) } 50 \text { a } 60 \text { 'de } \\
\text { exercícios contínuo } \\
\text { com carga aumentada } \\
\text { EA; ER }\end{array}$ & $\begin{array}{l}3 \text { / semana } 50- \\
60 \text { 'nas } \\
\text { primeiras } 2 \mathrm{~h} \\
\text { sessão, durante } \\
12 \text { semanas }\end{array}$ & $\begin{array}{l}\text { Berg balance scale } \\
\text { Postural control: Advance Mechanical } \\
\text { Technology Inc. (AMTI - AccuGait) } \\
\text { forceplate } \\
\text { ebody mass } \\
\text { Six-minutes-walking-test (6MWT) } \\
\text { 30s sit-to-stand (ST30s) test }\end{array}$ \\
\hline 9 & $\begin{array}{l}\text { Effect of Exercise } \\
\text { Performed during } \\
\text { Hemodialysis: Strength } \\
\text { versus Aerobic. Brasil } \\
2013\end{array}$ & $\begin{array}{l}\text { De Lima, } \\
\text { M. C., et. } \\
\text { al }\end{array}$ & RCT & $1 . \mathrm{C}$ & 33 & $\begin{array}{l}\text { Comparar dois tipos de } \\
\text { exercícios físicos (força } \\
\text { vs. aeróbica) e sua } \\
\text { influência na força } \\
\text { muscular, capacidade } \\
\text { funcional, função } \\
\text { pulmonar e QV }\end{array}$ & $\begin{array}{l}\text { Grupo de controle - } \\
\text { sem intervenção, } \\
\text { Grupo ER } \\
\text { Grupo EA }\end{array}$ & $\begin{array}{l}\text { 3/semana G2 } \\
15 \text { repetições } \\
\text { G3 15' } \\
8 \text { semanas, } \\
\text { durante as } \\
\text { primeiras } 3 \text { h } \\
\text { de HD; }\end{array}$ & $\begin{array}{l}\text { A máxima } \\
\text { pressão inspiratória (PImáx) e pressão } \\
\text { expiratória máxima (PEmáx) foram } \\
\text { avaliadas através de um } \\
\text { manovacuômetro analógico; } \\
\text { Teste de etapa (ST) por 4', } \\
\text { quantificando o número das etapas } \\
\text { alcançadas (NSA); } \\
\text { Resultados de uréia, hemoglobina, } \\
\text { potássio, cálcio, } \\
\text { e concentração de fósforo, } \\
\text { hematócrito } \\
\text { KDQoL-SF } 1.3\end{array}$ \\
\hline
\end{tabular}




\begin{tabular}{|c|c|c|c|c|c|c|c|c|c|}
\hline$E$ & $\begin{array}{c}\text { Título Estudo, Pais, } \\
\text { Ano }\end{array}$ & Autor & TE & NE & $N$ & Objetivo & $\begin{array}{l}\text { Intervenção/ } \\
\text { Exercício }\end{array}$ & $\begin{array}{l}\text { Duração/ } \\
\text { Frequência }\end{array}$ & Avaliação \\
\hline 10 & $\begin{array}{l}\text { Effect of resistance } \\
\text { exercise intradialytic in } \\
\text { renal patients chronic in } \\
\text { hemodialysis. Brasil } \\
2013\end{array}$ & $\begin{array}{l}\text { Ribeiro, } \\
\text { R., et. al }\end{array}$ & RCT & 1.c & 60 & $\begin{array}{l}\text { Estudar o papel do } \\
\text { exercício resistido no } \\
\text { tratamento e na QV }\end{array}$ & $\begin{array}{l}\text { Grupo 1: DM com DRC } \\
\text { ER; Grupo 2: DM com } \\
\text { DRC sem intervenção; } \\
\text { Grupo 3: DRC e ER, } \\
\text { Grupo 4: DRC Sem } \\
\text { intervenção }\end{array}$ & $\begin{array}{l}3 \text { / semana. } \\
3 \text { séries de } 12 \\
\text { repetições } \\
8 \text { semanas, }\end{array}$ & $\begin{array}{l}\text { Avaliação de creatinina, ureia, } \\
\text { potássio, glicemia de jejum; } \\
\text { índice de Kt/v } \\
\text { Teste de força manual } \\
\text { Medical Outcomes Study } 36 \text { (SF36) }\end{array}$ \\
\hline 11 & $\begin{array}{l}\text { Exercise Training During } \\
\text { Hemodialysis Reduces } \\
\text { Blood Pressure and } \\
\text { Increases Physical } \\
\text { Functioning and Quality } \\
\text { of Life. Brasil } \\
2010\end{array}$ & $\begin{array}{l}\text { Reboredo } \\
\text {, M. de } \\
\text { M., et. al }\end{array}$ & QE & $2 . d$ & 18 & $\begin{array}{l}\text { Avaliar os efeitos da } \\
\text { supervisão treino } \\
\text { aeróbico sobre a } \\
\text { atividade física, } \\
\text { pressão arterial, QV e } \\
\text { dados laboratoriais. }\end{array}$ & $\begin{array}{l}\text { Fase de controle (12 } \\
\text { semanas antes da } \\
\text { intervenção) 10' } \\
\text { exercícios de } \\
\text { alongamento dos } \\
\text { membros inferiores } \\
\text { - Fase de intervenção } \\
\text { consistiu no treino com } \\
\text { EA }\end{array}$ & $\begin{array}{l}\text { 3/ Semana } \\
12 \text { Semanas } \\
\text { controlo e } \\
12 \text { Semanas de } \\
\text { intervenção } \\
\text { Nas primeiras } 2 \\
\text { h de HD. } \\
33 \text { ' } \\
\text { final de } 12 \\
\text { semana 37.2' } \\
\text { min } \\
\text { Durante } \\
\text { 24semanas }\end{array}$ & $\begin{array}{l}\text { Teste de caminhada de 6' (6MWT) } \\
\text { Borg scale } \\
2 \text { MAPA } \\
\text { Medical Outcomes Study 36-Item } \\
\text { Short-Form Health Survey (SF-36) } \\
\text { Colheitas de amostras de sangue } \\
\text { Kt/V }\end{array}$ \\
\hline 12 & $\begin{array}{l}\text { Effect of intradialytic } \\
\text { aerobic exercise on } \\
\text { serum electrolytes levels } \\
\text { in hemodialysis } \\
\text { patients. Irão } \\
2010\end{array}$ & $\begin{array}{l}\text { Makhloug } \\
\text { h, A., et. } \\
\text { al }\end{array}$ & RCT & $1 . c$ & 47 & $\begin{array}{l}\text { Determinar o impacto } \\
\text { de um programa de } \\
\text { exercícios } \\
\text { intradialíticos, nos } \\
\text { níveis séricos de } \\
\text { eletrólitos e } \\
\text { hemoglobina. }\end{array}$ & $\begin{array}{l}\text { 1.Grupo EA } \\
\text { 2. Grupo controlo: sem } \\
\text { intervenção } \\
\text { - }\end{array}$ & $\begin{array}{l}3 \text { / Semana, } \\
15, \\
\text { Durante } 2 \\
\text { meses. }\end{array}$ & $\begin{array}{l}\text { Parâmetros } \\
\text { sanguíneos, fosfato, potássio calcio } \\
\text { sérico e hemoglobina, }\end{array}$ \\
\hline 13 & $\begin{array}{l}\text { Implementation of } \\
\text { exercise training } \\
\text { programs in a } \\
\text { hemodialysis unit: } \\
\text { effects on physical } \\
\text { performance. Italia } \\
2011\end{array}$ & $\begin{array}{l}\text { Bulckaen } \\
\text {, M., } \\
\text { et.al }\end{array}$ & $\mathrm{RCT}$ & 2.d & 18 & $\begin{array}{l}\text { Avaliar os efeitos no } \\
\text { desempenho físico de } 2 \\
\text { programas diferentes } \\
\text { de } 6 \text { meses de } \\
\text { exercício adaptado à } \\
\text { capacidade física. }\end{array}$ & $\begin{array}{l}\text { Grupo } 1 \text { - programa de } \\
\text { exercícios em casa + } \\
\text { EA } \\
\text { Grupo } 2 \text { - EA + } \\
\text { programa de treino } \\
\text { físico + treino com } \\
\text { supervisão. }\end{array}$ & $\begin{array}{l}3 \text { /Semana } \\
\text { Nas primeiras } 2 \\
\text { horas de } \\
\text { diálise, ou por } \\
30^{\prime}, \\
\text { Durante } 6 \\
\text { meses. }\end{array}$ & $\begin{array}{l}\text { 6-Minute walk test (6MWT) } \\
\text { Step-diary } \\
\text { Treadmill test, avaliar capacidade de } \\
\text { resistencia } \\
\text { Índice de massa corporal (IMC) } \\
2 \text { Peso corporal } \\
\text { Índice de resistidos à eritropoietina } \\
\text { (ERI) } \\
\text { Avaliados o hematócrito e soro de } \\
\text { eletrólitos, uréia, albumina e proteína } \\
\text { C reativa. Kt / V } \\
\text { Normalized protein nitrogen } \\
\text { appearance (nPNA) }\end{array}$ \\
\hline 14 & $\begin{array}{l}\text { The Effect of Prolonged } \\
\text { Intradialytic Exercise in } \\
\text { Hemodialysis Efficiency } \\
\text { Indices. Grécia } \\
2011\end{array}$ & $\begin{array}{l}\text { Giannaki, } \\
\text { C. D., et. } \\
\text { al }\end{array}$ & $\mathrm{RCT}$ & 1.c & 10 & $\begin{array}{l}\text { Verificar se o exercício } \\
\text { intra-dialítico aprimora } \\
\text { a remoção de toxinas, } \\
\text { diminuindo a resistidos } \\
\text { intersompartimental, } \\
\text { um grande } \\
\text { impedimento para a } \\
\text { remoção de toxinas. }\end{array}$ & $\begin{array}{l}\text { Grupo 1: EA } \\
\text { Grupo controlo- sem } \\
\text { intervenção }\end{array}$ & $\begin{array}{l}\text { No mesmo dia } \\
\text { da semana de } 2 \\
\text { semanas } \\
\text { consecutivas. } \\
3 \mathrm{~h} \\
\text { Durante } 2 \\
\text { meses }\end{array}$ & $\begin{array}{l}\text { Colheitas de amostra de sangue antes } \\
\text { e depois da HD } \\
\text { Peso } \\
\text { Kt/V } \\
{ }^{2} \text { The reduction ratios of BUN and } \\
\text { creatinin } \\
\text { Borg RPE scale } \\
\text { SF- } 36 \text { Dimensão da saúde física } \\
\text { sit-to-stand test (STS-60 } \\
\text { NSRI walk test } \\
\text { STS- } 60\end{array}$ \\
\hline 15 & $\begin{array}{l}\text { Effect of Intradialytic } \\
\text { Versus Home-Based } \\
\text { Aerobic Exercise Training } \\
\text { on Physical Function and } \\
\text { Vascular Parameters in } \\
\text { Hemodialysis Patients: A } \\
\text { Randomized Pilot Study. } \\
\text { Australia } \\
2010\end{array}$ & $\begin{array}{l}\text { Koh, K. } \\
\text { P., et. al }\end{array}$ & RCT & $1 . \mathrm{C}$ & 70 & $\begin{array}{l}\text { Comparar os efeitos de } \\
6 \text { meses de treino físico } \\
\text { supervisionado } \\
\text { intradialítico versus } \\
\text { treino físico domiciliar } \\
\text { ou atividade vida diaria } \\
\text { em função e rigidez } \\
\text { arterial em doentes em } \\
\text { HD. }\end{array}$ & $\begin{array}{l}\text { Grupo EA } \\
\text { Grupo de exercício } \\
\text { domiciliar } \\
\text { Grupo de controlo- } \\
\text { sem intervenção }\end{array}$ & $\begin{array}{l}3 \text { / semana } \\
15 \text { 'semana nas } \\
\text { duas primeiras } \\
\text { semanas e } \\
\text { progredir para } \\
30^{\prime} \text { na semana } \\
12 \text { e } 45^{\prime} \text { por } \\
\text { semana na } \\
\text { semana } 24 . \\
\text { Durante } 6 \\
\text { meses }\end{array}$ & $\begin{array}{l}\text { Borg RPE of } 12-13 \\
\text { 6-Minute walk distance, } \\
\text { TUG, } \\
\text { Grip strength test } \\
\text { Medical Outcomes Short-Form 36-Item } \\
\text { Health Survey }\end{array}$ \\
\hline
\end{tabular}




\begin{tabular}{|c|c|c|c|c|c|c|c|c|c|}
\hline$E$ & $\begin{array}{c}\text { Título Estudo, Pais, } \\
\text { Ano }\end{array}$ & Autor & TE & NE & $\mathbf{N}$ & Objetivo & $\begin{array}{l}\text { Intervenção/ } \\
\text { Exercício }\end{array}$ & $\begin{array}{l}\text { Duração/ } \\
\text { Frequência }\end{array}$ & Avaliação \\
\hline 16 & $\begin{array}{l}\text { Effect of Resistance } \\
\text { Exercises on the } \\
\text { Indicators of Muscle } \\
\text { Reserves and Handgrip } \\
\text { Strength in Adult } \\
\text { Patients on } \\
\text { Hemodialysis, Mexico } \\
2015\end{array}$ & $\begin{array}{l}\text { Olvera- } \\
\text { Soto, M. } \\
\text { G., et. al }\end{array}$ & RCT & 1.c & 61 & $\begin{array}{l}\text { Avaliar o efeito de } \\
\text { exercícios resistidos } \\
\text { realizados durante as } \\
\text { sessões de hemodialise } \\
\text { nos indicadores } \\
\text { antropométricos } \\
\text { musculares e força de } \\
\text { flexão de mão em } \\
\text { indivíduos sedentários } \\
\text { malnutridos com } \\
\text { doença renal em último } \\
\text { grau. }\end{array}$ & $\begin{array}{l}\text { Grupo-Controlo- sem } \\
\text { intervenção } \\
\text { Grupo-ER. }\end{array}$ & $\begin{array}{l}2 \text { /Semana. } \\
50 \text { ' realizadas } \\
\text { durante a } \\
\text { segunda hora } \\
\text { HD } \\
\text { Durante } 12 \\
\text { semanas }\end{array}$ & $\begin{array}{l}\text { Equação de Jellife e Jellife; } \\
\text { Equação de Heymsfield e cols; } \\
\text { Handgrip strength- Analogue Handgrip } \\
\text { Dynamometer } \\
\text { IMC }\end{array}$ \\
\hline 17 & $\begin{array}{l}\text { Effects of resistance } \\
\text { exercise training on acyl- } \\
\text { ghrelin and } \\
\text { obestatin levels in } \\
\text { hemodialysis patients } \\
\text { Brasil } \\
2015\end{array}$ & $\begin{array}{l}\text { Moraes, } \\
\text { C., } \\
\text { Marinho, } \\
\text { S., et. al }\end{array}$ & $\mathrm{RCT}$ & 2.d & 52 & $\begin{array}{l}\text { O objetivo deste estudo } \\
\text { é avaliar os efeitos de } \\
\text { um programa de } \\
\text { exercícios resistidos } \\
\text { nas hormonas do } \\
\text { apetite, na composição } \\
\text { corporal e estado } \\
\text { nutricional }\end{array}$ & $\begin{array}{l}\text { Grupo controlo- sem } \\
\text { intervenção } \\
\text { Grupo de ER }\end{array}$ & $\begin{array}{l}\text { Durante as } \\
\text { primeiras } 2 \mathrm{~h} \\
\text { de } \mathrm{HD}, \\
\text { 3/semana, } \\
\text { Durante } 6 \\
\text { meses }\end{array}$ & $\begin{array}{l}\text { 1-Repetition Maximum Test (1RM); } \\
\text { Dados bioquímicos de rotina após } \\
\text { jejum noturno (Obestatina, acil- } \\
\text { grelina, bioquímica), } \\
\text { adapted Subjective Global Assessment } \\
\text { (SGA } \\
\text { Dados antropométricos (peso corporal } \\
(\mathrm{kg}) \text {, altura }(\mathrm{m}) \text {, circunferência da } \\
\text { cintura }(\mathrm{CC}, \mathrm{cm}) \text {, e dobras cutâneas } \\
(\mathrm{mm})) \\
\text { IMC } \\
\text { SF36 }\end{array}$ \\
\hline 18 & $\begin{array}{l}\text { Effects of Aerobic } \\
\text { Exercise During } \\
\text { Hemodialysis on Physical } \\
\text { Functional Performance } \\
\text { and Depression. } \\
\text { Taiwan, China } \\
2015\end{array}$ & $\begin{array}{l}\text { Liu, Y.- } \\
\text { M., } \\
\text { Chung, } \\
\text { et. al }\end{array}$ & $\mathrm{RCT}$ & 2.d & 24 & $\begin{array}{l}\text { Avaliar os efeitos do } \\
\text { exercício aeróbico no } \\
\text { desempenho da } \\
\text { atividade física e na } \\
\text { depressão. }\end{array}$ & $\begin{array}{l}\text { Grupo Controlo- sem } \\
\text { intervenção } \\
\text { Grupo } \\
\text { EA }\end{array}$ & $\begin{array}{l}\text { 3/ Semana } \\
20 \\
\text { Durante } 12 \\
\text { semanas }\end{array}$ & $\begin{array}{l}\text { 6-min walk test } \\
(6 \mathrm{MWT}) \\
\text { sit-to-stand test (STS-60) } \\
\text { Chinese version of the Beck Depression } \\
\text { Inventory II (C-BDI-II } \\
\text { Dados bioquímicos }\end{array}$ \\
\hline 19 & $\begin{array}{l}\text { Aerobic Exercise } \\
\text { Improves Signs of } \\
\text { Restless Leg Syndrome in } \\
\text { End Stage Renal Disease } \\
\text { Patients Suffering } \\
\text { Chronic Hemodialysis. } \\
\text { Irão } \\
2013\end{array}$ & $\begin{array}{l}\text { Mortazavi } \\
\text {, M. ,et.al }\end{array}$ & $\mathrm{RCT}$ & $1 . c$ & 26 & $\begin{array}{l}\text { Avaliar o efeito do } \\
\text { exercício na síndrome } \\
\text { de pernas inquietas e } \\
\text { QV }\end{array}$ & $\begin{array}{l}\text { Grupo Controlo- sem } \\
\text { intervenção } \\
\text { Grupo de EA }\end{array}$ & $\begin{array}{l}3 / \text { Semana; } \\
30 \text { ' entre as } \\
\text { horas } 2 \text { e } 3 \\
\text { durante a } \\
\text { diálise } \\
\text { Durante } 16 \\
\text { semanas. }\end{array}$ & $\begin{array}{l}\text { Borg scale } \\
\text { Avaliação de pressão arterial e a } \\
\text { frequência cardíaca determinadas } \\
\text { antes e depois da diálise e nas horas } 2 \\
\text { e } 3 \text { durante a diálise } \\
\text { Questionário RLSQ } \\
\text { SF-63 }\end{array}$ \\
\hline
\end{tabular}

E-Estudo; TE-Tipo de estudo; NE- Nivel de Evidencia; N-Amostra; RCT - Randomized controlled trial; QE - Quasi-experimental

\section{Caraterísticas dos estudos selecionados}

Foram selecionados para analise final 19 estudos, 2 estudos quasi-experimentais $(17,18)$ e os restantes estudos randomizados controlados $(19,20,21,22,23,24,25,26,27,28,29,30,31,32,33,34,35)$.

Relativamente ao tipo de EFI, os estudos apresentam resultados de exercícios isolados e/ou combinados. Em 2 artigos foram realizados exercícios resistidos ${ }^{(27,34)}$ e em 8 exercícios aeróbios $(18,28,29,30,31,32,33,35)$. Em 3 artigos compararam intervenções dos dois tipos de exercícios $(23,24,26)$ e em 6 a intervenção combinou exercícios aeróbios e resistidos $(17,19,20,21,22,25)$. Para os exercícios aeróbios a maioria dos estudos utilizou cicloergómetro e para os resistidos utilizaram pesos e bandas elásticas.

Quanto aos grupos de intervenção verificamos que 12 artigos têm 2 grupos de comparação $(17,18,19,20,22,28$, $29,30,31,33,34,35)$ e 5 artigos apresentam 3 grupos de comparação $(21,24,25,26,32)$. Existem 2 artigos que apresentam 4 grupos de intervenção ${ }^{(23,27)}$, verificamos que um deles tem um grupo para exercícios resistidos, outro para exercícios aeróbios e mais um para exercícios combinados.

A frequência dos exercícios varia entre as 3 semanas e os 6 meses, sendo que a duração de 12 semanas é a mais frequente. Comparando todos os estudos averiguamos que a maioria dos estudos faz a intervenção 3 vezes por semana correspondendo aos dias de HD semanal.

Nos 19 estudos foram avaliados os seguintes parâmetros: qualidade de vida (7); alterações na função renal (7); capacidade física funcional (6); eficácia da HD (4); força muscular (4); depressão (2). Os seguintes parâmetros, foram avaliados apenas uma vez: alterações cardiovasculares; autonomia nas atividades de vida diária; sono; equilíbrio e síndrome de pernas inquietas.

\section{Função Motora}

Nesta categoria englobamos os resultados relacionados com a capacidade física funcional, a força muscular e o equilíbrio.

A capacidade funcional, foi avaliada em 6 artigos, mas apenas, em 5 artigos se verificou benefício estaticamente significativo. $(17,18,19,28,32)$ Maynard et al (19) verificaram que um programa utilizando realidade virtual associado a exercícios aeróbios e resistidos durante 12 semanas melhorou a capacidade funcional $(p<0,001)$ e o desempenho físico $(p=0,021)$ da amostra. 
Rhee et al (17) também aplicaram exercícios combinados a uma amostra de 22 indivíduos e concluíram que houve um aumento na capacidade funcional $(p<0,05)$.

Por outro lado, Koh et al ${ }^{(32)}$ verificaram, que houve benefício na capacidade funcional nos 2 grupos, mas sem diferença estaticamente significativa, entre os dois. Um realizou exercícios intradialítico e o outro grupo exercício no domicílio. Esta intervenção foi baseada em exercícios aeróbios e teve a duração de 6 meses.

A força muscular foi avaliada em 4 artigos $(20,25,26,33)$ nos quais se constatou melhoria. Desai et al (20) numa amostra de 18 indivíduos verificou que após um programa de exercícios combinados, houve um aumento da força muscular, nomeadamente na força de preensão manual $(p<0,01)$ e na de força de pinça ( $p$ $<0,05)$. Olvera-Soto et al (33) após aplicarem um programa de exercícios resistidos observaram que houve um aumento na circunferência do músculo do braço $(p=0,001)$, área do músculo do braço $(p=0,002)$ e força de preensão manual, entre as medidas basais e finais $(p<0,05)$.

Em 2017 Carletti et al (25) verificaram que para o equilíbrio e força muscular, apesar de haver melhoria, esta não apresentava diferença estatística entre os 3 grupos que realizaram exercícios aeróbios simples e exercícios combinados.

\section{Depressão}

O impacto da depressão é analisado em 2 artigos ${ }^{(17,18)}$. Rhee et al (17) concluíram que um programa de exercícios combinados teve benefícios na depressão quando comparado com o grupo de controlo $(p<0,05)$.

Após o término do programa de exercícios aeróbios, Liu et al (18) verificaram que os scores médios de depressão indicaram depressão major no grupo de controlo e depressão leve no grupo experimental $(p=0,001)$.

\section{Qualidade de Vida}

A Qualidade de Vida foi avaliada em 7 artigos (17, $22,26,27,28,34,35)$, sendo que os autores utilizaram diferentes escalas de avaliação. Dos 7 artigos verificamos que, 5 referiram benefícios do exercício face à qualidade de vida $(22,26,27,28,34)$, enquanto 2 não apresentaram uma melhoria significativa ${ }^{(17,35)}$.

Paluchamy e Vaidyanathan (22) verificaram que houve um aumento significativo $(p<0,05)$ na qualidade de vida após 12 semanas de uma intervenção combinada de exercícios aeróbios e resistidos. Em 2013 Ribeiro et al. (27) observaram que, um programa de exercícios resistidos contribuiu para uma melhoria na Qualidade de vida $(p<0,001)$. Reboredo et al. ${ }^{(28)}$ constataram uma melhoria significativa nas dimensões da atividade física, relação social e saúde mental do SF-36.

Em sentido contrário verificamos que Rhee et al. (17) não obtiveram diferenças, relacionadas com a avaliação da qualidade de vida, após 6 meses de exercícios combinados. Também Mortazavi et al. (35) não verificaram existirem diferenças entre os dois grupos, após a realização de um programa de exercícios aeróbios.

\section{Atividade Física}

Um estudo realizado na Coreia do Sul por Cho et al. (23) dividiu a amostra em 4 grupos sendo aplicada a intervenção durante 12 semanas. 0 primeiro grupo serviu de controlo e os restantes realizaram exercícios aeróbios, resistidos e combinados respetivamente. Analisamos que os grupos que realizaram exercício apresentaram menos períodos de inatividade física sendo a diferença maior no grupo que realizou exercícios aeróbicos $(p=0,01)$.

\section{Sono}

A qualidade de sono foi avaliada apenas em 1 artigo (23), pela fragmentação do padrão de sono. Os autores concluíram que face ao grupo de controlo, tanto os exercícios aeróbios $(p=0,03)$ e exercícios resistidos $(p=0,01)$, melhoram significativamente a qualidade de sono.

\section{Eficácia da Hemodialise}

Em 7 artigos $(19,22,24,26,27,29,31)$ foi analisado o efeito do exercício e a sua influência na função renal.

Observamos em 3 artigos $(19,22,24)$ com programas de exercícios combinados, a melhoria na função renal, nomeadamente nos valores séricos de ureia. Brown et al. ${ }^{(24)}$ verificaram que o grupo que realizou o exercício apresentou benefício, na função renal, em relação ao grupo de controlo. Os mesmos autores também constataram que o aumento da intensidade do exercício, não provocou diferenças estatísticas significativas.

Nos restantes artigos verificamos que a prática de exercício aeróbio ou resistido trouxe benefícios na função renal destes doentes $(26,27,29,31)$.

Dos artigos analisados, observamos que 4 avaliaram o Kt/V ${ }^{(17,20,22,31)}$. Em dois estudos verificamos que uma intervenção de exercícios combinados levou a uma melhoria significativa do Kt/V $(p<0,01)^{(20,22)}$, em programas de duração de 3 e 4 meses, respetivamente. Por outro lado, Rhee et al. (17) após 6 meses de intervenção, não observou alterações significativas na avaliação do Kt/V, após a realização de um programa de exercícios semelhante ao anterior. Giannak et al. ${ }^{(31)}$ concluíram que após 2 meses de exercícios aeróbios o $\mathrm{Kt} / \mathrm{V}$, melhorou significativamente na sessão de exercícios em comparação com a sessão sem exercícios $(p=0,05)$.

\section{Síndrome das Pernas Inquietas}

Em 2013, Mortazavi et al. (35) analisaram a influência de exercícios aeróbios durante 16 semanas nos sintomas da síndrome das pernas inquietas. Após a intervenção realizada concluíram, que houve diferença 
estatisticamente significativa entre o grupo de controlo e o grupo experimental $(p=0,003)$.

\section{DISCUSSÃO}

Nesta revisão sistemática incluímos estudos controlados randomizados e estudos quasi-experimentais, que demonstraram evidência científica relacionada com os benefícios do $\mathrm{EFI}$. Dos estudos incluídos a amostra menor incluiu 7 doentes e a maior 70 , sendo que o total de doentes incluídos em todos os estudos é de 606 .

Verificou-se que existiu, preocupação em estudar o impacto do EFI, em várias vertentes: física, psicológica e social. A vertente física foi a mais estudada, através da avaliação da capacidade funcional, da força muscular e na eficácia da HD. Os estudos, apresentam várias metodologias e escalas de avaliação dos parâmetros analisados, o que dificultou de alguma forma o agrupar dos resultados.

Para avaliação da capacidade funcional física os testes mais utilizados, foram o Teste de deslocamento (Timed up and go-TUG), Teste de sentar e repousar (Sit-tostand -STS-60) e o Teste de caminhada de 6' (6MWT). $\mathrm{Na}$ nossa opinião a utilização destes testes deve-se ao fato de serem fiáveis, e como refere Morales ${ }^{(36)}$ são bem tolerados pela maioria dos doentes, além de requererem pouco equipamento para a sua realização (37). A força muscular foi avaliada com o 6MWT, TUG, Manovacuómetro analógico, Teste de etapa (ST) por 4', Handgrip strength- Analogue Handgrip Dynamometer.

A QV, foi o segundo parâmetro mais avaliado, o questionário mais utilizado foi SF-36, por ser curto e de fácil aplicabilidade. Em apenas um artigo foi aplicado, um questionário dirigido à população em estudo, o Kidney Disease Quality of Life Short Form (KDQOL$\mathrm{SF}^{\mathrm{TM}}$ ), que para além de incluir o SF-36, inclui 43 itens específicos da doença renal, validado e difundido em vários países, incluindo Portugal (38). Silva et al ${ }^{(39)}$,referem que um programa de exercícios, durante o período intradialítico, aumenta significativamente a QV do doente com DRC, a mesma informação foi obtida em 5 dos estudos incluídos nesta revisão sistemática.

A função renal avaliada através de parâmetros analíticos, foi também uma preocupação da maioria dos estudos, no entanto, apenas 7 apresentam estes resultados como primary outcome. A eficácia da dialise foi avaliada através do Kt/V e pela taxa de remoção da ureia. Mohseni et al. (40) referem que aumentar a eficácia dialítica é uma forma efetiva de melhorar o prognóstico do doente em HD.

A realização de exercício físico, na primeira hora da HD é utilizada na maioria dos estudos. Kosmadakis et al. ${ }^{(6)}$,referem que durante a HD a mudança de fluídos intravasculares para o espaço intersticial conduz a uma redução da volémia, e consequente á hipotensão, pelo que, recomendam que o programa de exercício decorra nas duas primeiras horas de HD.

Carft e Perna (41), consideram que a eficácia do exercício na diminuição de sintomas da depressão encontra-se bem definida. Também referem que o foco deve estar na frequência do exercício e não na sua duração ou intensidade. Como podemos verificar nos artigos incluídos o exercício trouxe benefícios face à sintomatologia depressiva, referida pelos doentes.

Podemos concluir, que independentemente do tipo de programa de EFI implementado, todos apresentaram benefícios, exceto quando realizados num curto espaço de tempo, como podemos verificar no estudo de Brown, et al (24), onde os 22 doentes, não apresentaram melhoria significativa, num programa de exercício avaliado ao fim de 3 semanas.

Os artigos analisados utilizaram exercícios aeróbios e resistidos. Segundo Pereira (42) um programa intradialítico aeróbio de cicloergómetro, representa uma estratégia útil e fácil de implementar para reduzir a sintomatologia associada à DRC. Também Novo et al ${ }^{(43)}$, referem que o exercício aeróbio produz uma clara melhoria na deambulação dos doentes, mas, em termos de força muscular as melhorias não são significativas. Grande parte destes estudos, realiza exercícios combinados entre aeróbios e resistidos. De acordo com os autores estudados há benefício em juntar estes dois tipos de programas, não só na capacidade funcional mas também a nível da força muscular.

Verificamos também, a existência de grande adesão aos programas de EFI. Como refere Martins (44), os protocolos de treino aeróbio intradialítico são de execução simples, pouco dispendiosos, melhoram a capacidade funcional e sem prejuízo na eficácia dialítica.

De acordo com a literatura encontrada, pensamos que o exercício físico deveria ser uma recomendação incluída no tratamento de HD. Devendo a sua prescrição ser individualizada, de acordo com os fatores de risco desta população. A sua realização deverá ser sempre supervisionada por um profissional de saúde.

\section{CONCLUSÃO}

Conclui-se que, a quase totalidade dos artigos, demonstram efeitos benéficos na realização do exercício físico, não só para capacidade funcional e a força muscular, mas também na QV e na melhoria da eficácia da HD.

A maioria dos artigos apresenta como critério de inclusão, a estabilidade dos doentes, pelo que não é claro, se os benefícios estão limitados a estes doentes. Portanto, protocolos individualizados, para doentes com comorbilidades associadas, precisam ser mais estudados.

Apesar dos benefícios expostos, a prática do EFI, não é uma prática habitual. Uma das hipóteses a ser considerada, pode ser o desconhecimento dos benefícios, por parte das equipas de saúde, uma vez que do ponto de vista económico, não é necessário um grande investimento por parte dos centros de HD. Recomendamos como áreas para futuras pesquisas, os motivos apresentados pelos profissionais de saúde para a não realização de EFI. 


\section{REFERÊNCIAS BIBLIOGRÁFICAS}

1. Basile, C. (2008). The long-term prognosis of acute kidney injury: acute renal failure as a cause of chronic kidney disease. J Nephrol, 21(5), 657-662. Recuperado de https://pubmed.ncbi.nlm.nih.gov/18949719/

2. Feehally, J., Floege, J., Tonelli, M., Johnson, R. J. (2018). Comprehensive Clinical Nephrology $\left(6^{\text {th }}\right.$ Edition). Oxford: ElsevierHealth Sciences Division.

3. National Kidney Foundation. (2006). Clinical practice guidelines for vascular access. Recuperado de https://www.kidney.org/sites/default/files/docs/12-500210_jag_dcp_guidelines-hd_oct06_sectiona_ofc.pdf

4. Sociedade Portuguesa de Nefrologia. (2019). Relatórios Anuais 2018. Recuperado em 29 de Junho, 2020 de http://www.bbg01.com/cdn/rsc/spnefro/gabreg/305/Relatrios Anuais2018.pdf

5. Astor, B.C., Eustace, J.A., Powe, N.R., Klag, M.J., Fink, N.E., Coresh, J. (2005). Type of vascular access and survival among incident hemodialysis patients: the CHOICE Study. J Am Soc Nephrol, 16(5), $1449-1451$ https://doi.org/10.1681/asn.2004090748

6. Kosmadakis, G. C., Bevington, A., Smith, A. C., Clapp, E. L., Viana, J. L., Bishop, N. C., \& Feehally, J. (2010). Physical exercise in patients with severe kidney disease. Nephron Clin Pract, 115(1), c7-c16. https://doi.org/10.1159/000286344

7. Chazot, C., Laurent, G., Charra, B., Blanc, C., VoVan, C., Jean, G., et al. (2001). Malnutrition in long-term haemodialysis survivors. Nephrol Dial Transplant, 16(1), 61-69. https://doi.org/10.1093/ndt/16.1.61

8. World Health Organization. Global Recomendations on Phisical Activity for health. 2010. Recuperado em 29 de Junho, 2020; de https://www.who.int/dietphysicalactivity/global-PA-recs2010.pdf

9. Moura, et all. Efeitos do exercício físico durante a hemodiálise em indivíduos com insuficiência renal crônica: uma revisão. 2008; Sciello. Recuperado em 20 de junho de 2020 de https: / / www.scielo.br/scielo.php?pid=S180929502008000100014\&script=sci_arttext

10. Parsons, T. L., Toffelmire, E. B., \& King-VanVlack, C. E. (2006). Exercise training during hemodialysis improves dialysis efficacy and physical performance. Arch Phys Med Rehabil, 87(5), 680687. https://doi.org/10.1016/j.apmr.2005.12.044

11. Reboredo, M. d. M., Henrique, D. M. N., Bastos, M. G., \& Paula, R. B. d. (2007). Exercício físico em pacientes dialisados. Rev. bras. med. Esporte, 13(6), 427-430. Recuperado de https://www.scielo.br/pdf/rbme/v13n6/14.pdf

12. Ramalho, A. (2005). Redação de Estudos e Projetos de Revisão Sistemática: com e sem meta análise: Formasau. Coimbra: Formação e Saúde, Lda.

13. Bettany-Saltikov, J. (2012). How to do a Systematic Literature Review in nursing - a step- bystep Guide. Glasgow: RCN Publishing Company.

14. PRISMA Group. Preferred Reporting Items for Systematic Reviews and Meta-Analyses. (s.l.). 2015; University of Ottawa/Oxford University. Recuperado em 18 de Junho de 2020 de: http://www.prisma-statement.org/PRISMAStatement/

15. Joanna Briggs Institute (2014). Joanna Briggs Institute Reviewers' Manual: 2014 edition. Recuperado em 15 de Junho, 2020 de http://joannabriggs.org/assets/docs/sumari/ReviewersManual2014.pdf

16. Magalhães, S. Tecnologias educativas destinadas à pessoa com dependência e/ou familiar cuidador: uma revisão sistemática da literatura. 2013. Porto. Dissertação de Mestrado em Enfermagem de Reabilitação apresentada na Escola Superior de Enfermagem do Porto. Recuperado a 23 de junho de 2020:https://comum.rcaap.pt/bitstream/10400.26/9384/1/Diss erta\%C3\%A7\%C3\%A3o_\%20S\%C3\%A9rgio_Magalh\%C3\%A3es_ep586. pdf

17. Rhee, S. Y., Song, J. K., Hong, S. C., Choi, J. W., Jeon, H. J., Shin, D. H., Ji, E. H., Choi, E.-H., Lee, J., Kim, A., Choi, S. W., \& Oh, J. (2019). Intradialytic exercise improves physical function and reduces intradialytic hypotension and depression in hemodialysis patients. The Korean Journal of Internal Medicine, 34(3), https://doi.org/10.3904/kjim.2017.020
18. Liu, Y.-M., Chung, Y.-C., Chang, J.-S., \& Yeh, M.-L. (2015). Effects of aerobic exercise during hemodialysis on physical functional performance and depression. Biological Research for Nursing, 17(2), https://doi.org/10.1177/1099800414539548

19. Maynard, L. G., de Menezes, D. L., Lião, N. S., de Jesus, E. M., Andrade, N. L. S., Santos, J. C. D., da Silva Júnior, W. M., Bastos, K. de A., \& Barreto Filho, J. A. S. (2019). Effects of Exercise Training Combined with Virtual Reality in Functionality and Health-Related Quality of Life of Patients on Hemodialysis. Games for Health Journal, 8(5), 339-348. https://doi.org/10.1089/g4h.2018.0066

20. Desai, M., Mohamed, A., \& Davenport, A. (2019). A pilot study investigating the effect of pedalling exercise during dialysis on 6 min walking test and hand grip and pinch strength. The International Journal of Artificial Organs, 42(4), 161-166. https://doi.org/10.1177/0391398818823761

21. Jeong, J. H., Biruete, A., Fernhall, B., \& Wilund, K. R. (2018). Effects of acute intradialytic exercise on cardiovascular responses in hemodialysis patients. Hemodialysis International. International Symposium on Home Hemodialysis, 22(4), 524-533. https://doi.org/10.1111/hdi.12664

22. Paluchamy, T., \& Vaidyanathan, R. (2018). Effectiveness of intradialytic exercise on dialysis adequacy, physiological parameters, biochemical markers and quality of life - A pilot study. Saudi Journal of Kidney Diseases and Transplantation : An Official Publication of the Saudi Center for Organ Transplantation, Saudi Arabia, 29(4), 902-910. https://doi.org/10.4103/1319-2442.239661

23. Cho, J.-H., Lee, J.-Y., Lee, S., Park, H., Choi, S.-W., \& Kim, J. C. (2018). Effect of intradialytic exercise on daily physical activity and sleep quality in maintenance hemodialysis patients. International Urology and Nephrology, 50(4), 745-754. https: / / doi.org/10.1007/s11255-018-1796-y

24. Brown, P. D. S., Rowed, K., Shearer, J., MacRae, J. M., \& Parker, K. (2018). Impact of intradialytic exercise intensity on urea clearance in hemodialysis patients. Applied Physiology, Nutrition, and Metabolism = Physiologie Appliquee, Nutrition et Metabolisme, 43(1), 101-104. https://doi.org/10.1139/apnm2017-0460

25. Carletti, C. O., da Costa Rosa, C. S., e Souza, G. D., Ramirez, A. P., Daibem, C. G. L., \& Monteiro, H. L. (2017). Intradialytic exercise and postural control in patients with chronic kidney disease undergoing hemodialysis. Fisioterapia Em Movimento, 30(2), 247-254. https://doi.org/10.1590/19805918.030.002.AO05

26. De Lima, M. C., Cicotoste, C. de L., Cardoso, K. da S., Forgiarini, L. A., Jr, Monteiro, M. B., \& Dias, A. S. (2013). Effect of exercise performed during hemodialysis: strength versus aerobic. Renal Failure, 35(5), https:// doi.org/10.3109/0886022X.2013.780977

27. Ribeiro, R., Coutinho, G. L., luras, A., Barbosa, A. M., Souza, J. A. C. de, Diniz, D. P., \& Schor, N. (2013). Effect of resistance exercise intradialytic in renal patients chronic in hemodialysis. Jornal Brasileiro de Nefrologia: 'orgao Oficial de Sociedades Brasileira e Latino-Americana de Nefrologia, 35(1), 13-19. https://doi.org/10.5935/01012800.20130003

28. Reboredo, M. de M., Henrique, D. M. N., Faria, R. de S., Chaoubah, A., Bastos, M. G., \& de Paula, R. B. (2010). Exercise training during hemodialysis reduces blood pressure and increases physical functioning and quality of life. Artificial Organs, 34(7), 586-593. https: //doi.org/10.1111/j.1525-1594.2009.00929.x

29. Makhlough, A., Ilali, E., Mohseni, R., \& Shahmohammadi, S. (2012). Effect of intradialytic aerobic exercise on serum electrolytes levels in hemodialysis patients. Iranian Journal of Kidney Diseases, 6(2), 119-123. Recuperado de https://pubmed.ncbi.nlm.nih.gov/22388610/

30. Bulckaen, M., Capitanini, A., Lange, S., Caciula, A., Giuntoli, F., \& Cupisti, A. (2011). Implementation of exercise training programs in a hemodialysis unit: effects on physical performance. Journal of Nephrology, 24(6), 790-797. https://doi.org/10.5301/JN.2011.6386

31. Giannaki, C. D., Stefanidis, I., Karatzaferi, C., Liakos, N., Roka, V., Ntente, I., \& Sakkas, G. K. (2011). The effect of prolonged intradialytic exercise in hemodialysis efficiency indices. ASAIO Journal (American Society for Artificial Internal Organs: 1992), 57(3),

213-218. 
https: / /doi.org/10.1097/MAT.0b013e318215dc9e

32. Koh, K. P., Fassett, R. G., Sharman, J. E., Coombes, J. S., \& Williams, A. D. (2010). Effect of intradialytic versus home-based aerobic exercise training on physical function and vascular parameters in hemodialysis patients: a randomized pilot study. American Journal of Kidney Diseases : The Official Journal of the National Kidney Foundation, 55(1), 88-99. https://doi.org/10.1053/j.ajkd.2009.09.025

33. Olvera-Soto, M. G., Valdez-Ortiz, R., López Alvarenga, J. C., \& Espinosa-Cuevas, M. de L. Á. (2016). Effect of Resistance Exercises on the Indicators of Muscle Reserves and Handgrip Strength in Adult Patients on Hemodialysis. Journal of Renal Nutrition: The Official Journal of the Council on Renal Nutrition of the National Kidney Foundation, 26(1), 53-60. https://doi.org/10.1053/j.jrn.2015.06.006

34. Moraes, C., Marinho, S., Lobo, J. C., Stockler-Pinto, M. B., Barros, A. F., Jacobson, L. V., da Nobrega, A. C. L., Rosa, M. L. G., \& Denise, M. (2015). Effects of resistance exercise training on acylghrelin and obestatin levels in hemodialysis patients. Renal Failure, 37(5), https://doi.org/10.3109/0886022X.2015.1033634

35. Mortazavi, M., Vahdatpour, B., Ghasempour, A., Taheri, D., Shahidi, S., Moeinzadeh, F., Dolatkhah, B., \& Dolatkhah, S. (2013). Aerobic exercise improves signs of restless leg syndrome in end stage renal disease patients suffering chronic hemodialysis. TheScientificWorldJournal, 2013, 628142. https://doi.org/10.1155/2013/628142

36. Morales, B. J. E., Palafox V. C. D., Rosas, R. M. J., García, C. M. M., Londoño V. A., Zamboni M. (2011). Six-minute walk test: a valuable tool for assessing pulmonary impairment. $J$ Bras Pneumol, 37(1), 110-117. Recuperado de https: / /www.scielo.br/scielo.php?script=sci_arttext\&pid=S1806$37132011000100016 \&$ ing $=p t \& t$ lng $=p t$

37. Fernandes, P. M., Pereira, N. H., Santos, A. C. B. da C., \& Soares, M. E. de S. M. (2012). Teste de caminhada de seis minutos: avaliação da capacidade funcional de indivíduos sedentários TT . Six-minute walk test: evaluation on the functional capacity of sedentary individuals. Rev. Bras. Cardiol. (Impr.), 25(3), 185-191. Recuperado http://www.rbconline.org.br/wpcontent/Archives/v25n3/v25n0 3a03.pdf

38. Ferreira, P., Anes, E. (2010) - Medição da qualidade de vida de insuficientes renais crónicos: criação da versão portuguesa do KDQOL-SF. Revista Portuguesa de Saúde Pública, Vol, 28(1), 31 $39 . \quad$ Recuperado http://www.scielo.mec.pt/pdf/rpsp/v28n1/v28n1a04.pdf

39. Silva, S. F., Pereira, A. A., Silva, W. A. H., Simôes, R., Barros Neto, J. de R. (2013). Physical therapy during hemodialyse in patients with chronic kidney disease. Jornal Brasileiro de Nefrologia: órgão Oficial de Sociedades Brasileira e LatinoAmericana de Nefrologia, 35(3), 170-176. http://dx.doi.org/10.5935/0101-2800.20130028

40. Mohseni, A, et al. The Effect of Intradialytic Aerobic Exercise on Dialysis Efficacy in Hemodialysis Patients: A Randomized Controlled Trial.2013, Oman Medical Journal. Recuperado em 20 de junho de 2020 de https://www.ncbi.nlm.nih.gov/pmc/articles/PMC3769128/pdf/ OMJ-D-13-00132.pdf

41. Craft, L., Perna, F. (2004). The Benefits of Exercise for the Clinically Depressed. The Primary Care Companion - Journal of Clinical Psychiatry, 6(3),104-111. https://doi.org/10.4088/PCC.v06n0301

42. Pereira, B., Boisseau, N. (2015). Beneficial effects of an intradialytic cycling training program in patients with end-stage kidney disease. Applied Physiology, Nutrition \& Metabolism, 40(6), 550-556. https://doi.org/10.1139/apnm-2014-0357

43. Novo, A., Travassos, F., Teixeira, F., Múrua, A., Azevedo, J., Fernandez, J. (2010). Avaliação funcional e efeitos de um treino aeróbio em pacientes hemodialisados com insuficiência renal crónica. In Promoção da Saúde e Actividade Fisica: contributos para o Desenvolvimento Humano, 16-24, ISBN: 978-972-669-9699. Vila Real: UTAD, Centro de Investigação em Desporto Saúde e Desenvolvimento Humano. Recuperado em 25 de Junho, 2020 de https://bibliotecadigital.ipb.pt/bitstream/10198/2625/1/livropromocao\%20da\%20saude.pdf

44. Martins, P., M., P. (2015). Implementação de um programa de exercício Intradialítico de maximização da função em utentes hemodialisados (Tese de Mestrado, Escola Superior de Enfermagem de Coimbra). Recuperado de file:///C:/Users/Utilizador/Downloads/D2014_10001222017_211 11003_1.pdf 